\title{
Immunological intervention with anti-immunoglobulin-E antibody to prevent asthma exacerbations
}

\author{
P. Chanez
}

The challenge to develop new therapeutic strategies to treat asthma is difficult, since drugs such as inhaled steroids and long-acting $\beta_{2}$-agonists are very successful and advocated by most national and international guidelines to be the long-term therapies of choice in most of the chronic situations [1]. The better understanding of the mechanisms of asthma as an inflammatory disease has led to the development of several new immunological approaches, which have been mostly disappointing after introduction in the clinic. The major reasons for this are linked to the complexity and the redundancy of the inflammatory processes in asthma, which are able to counterpoise the inhibition of a single cellular or molecular pathway [2].

Therefore, the global situation for asthma should be increasingly satisfactory based on the currently available treatments, but there are several remaining problems. First, the prevalence and the costs of the disease are still increasing. Secondly, most of the patients deny their asthma symptoms and severity and are mostly under-treated and uncontrolled [3]. If mild and moderate asthma can be controlled by the current strategies, poor compliance of the patients still contributes to the excess morbidity and costs. And finally, there is a group of patients that remains uncontrolled despite good compliance, because the severity of their disease often requires an addition of oral doses of corticosteroids to avoid exacerbations. Those patients have a poor quality of life and require several hospitalizations each year [4].

In this issue, SOLER et al. [5] report a large multicentre study showing the safety and efficacy of subcutaneous treatment with anti-immunoglobulinE (IgE) (monoclonal antibody rhuMAB-E25/omalizumab) of patients with moderate asthma. They demonstrate improved asthma control by anti-IgE therapy, as shown by a significant decrease in the number of asthma exacerbations. These data confirm and extend the previous findings by MiLgrom et al. [6] in relation to better asthma control, an inhaled steroid-sparing effect and the efficacy of this immunological strategy in elderly patients.

The role of IgE in the pathogenesis of allergic asthma is derived from different lines of evidence. Several epidemiological studies report close associations

Correspondence: P. Chanez, Clinique des Maladies Respiratoires, 34295-Montpellier-Cedex 5, France. Fax: 33467521848. between IgE levels and the presence of asthma [7]. Anti-IgE auto-antibodies have been described and block the binding of $\operatorname{IgE}$ to their high-affinity receptor [8]. Animal studies have confirmed the potential prevention of the occurrence of antigen-induced bronchoconstriction and bronchial eosinophil infiltration in sensitized mice treated by anti-IgE monoclonal antibody [9]. The anti-IgE potentially affects allergic diseases by binding the circulating $\operatorname{IgE}$ already present, to form inert complexes avoiding the cross linking on mast cells and other inflammatory cells and/ or preventing the synthesis of new $\mathrm{IgE}$, thereby avoiding the progression of airway inflammation.

The potential role of $\operatorname{IgE}$ in asthma in humans was demonstrated in humans by FAHY et al. [10] who showed the attenuation of both early- and late-phase responses to airway allergen challenge in allergic asthmatic patients by pretreatment with an anti-IgE monoclonal antibody. The reduction of sputum eosinophilia was additional evidence of a real antiinflammatory effect. Anti-IgE antibody was also effective in the treatment of seasonal allergic rhinitis [11].

In this issue of the European Respiratory Journal, SolÈr et al. [5] report their study in which 274 patients with moderate persistent allergic asthma (treated with $500-1,200 \mu \mathrm{g}$ daily beclomethasone) received subcutaneous IgE antibody or placebo therapy for 7 months. The number of asthma exacerbations requiring a short course of treatment by oral corticosteroids was reduced in the rhuMAB-E25 antibody group. Eighty-three per cent of patients on placebo had at least one exacerbation as compared to $35 \%$ in the anti$\operatorname{IgE}$ treated group. This difference remained the same despite the inhaled steroid (ICS) reduction strategy used. This ICS reduction was moderate but significantly greater in the anti-IgE group as compared to the placebo group. Despite this step down in ICS dose, there was a significant reduction of symptoms, rescue medication use and a small increase in airway function (morning peak expiratory flow (PEF) and forced expiratory volume in one second (FEV1)) in the anti-IgE group. The treatment with $\operatorname{IgE}$ antibody injected subcutaneously was well tolerated by all the patients, confirming previous safety data obtained using other routes of administration. Interestingly, there were no immunologically driven side-effects, such as the formation of anti-omalizumab antibodies or the occurrence of autoimmune diseases affecting the kidney or the skin. 
How can these results be interpreted? The heterogeneous clinical expression of asthma in humans suggests a process more complex than the one that is recreated using animal models. The exact role of $\mathrm{IgE}$ in the pathogenesis of asthma is still uncertain. Thus, the mechanisms of action of $\operatorname{IgE}$ antibody require further investigation. Allergic asthma affects the vast majority of the asthmatic patients with relatively mild forms of the disease, but the exact relationship between allergic sensitization and the occurrence of asthma symptoms is not always easy to demonstrate in the real world. Interestingly, patients with no demonstrable allergy seem to suffer from the same kind of inflammation in the airways as those with allergy, affecting their nose as well as their lower airways [12]. They tend to have a more severe disease and, therefore, they may be a further target for the anti-IgE strategy considering that some of them have elevated IgE levels. A systemic treatment may improve all kinds of symptoms including upper airway diseases, increasing adherence to treatment.

The study of Solèr et al. [5] is of great clinical importance as it shows a decrease in number and severity of asthma exacerbation, which are of real concern in this chronic disease. Furthermore, the tolerance of anti-IgE and the use of a subcutaneous treatment regimen may increase compliance in moderate asthma patients. The indirect evidence of an anti-inflammatory effect, as reflected by the decrease of the inhaled corticosteroid doses, might represent a good therapeutic alternative to be tested in the severe form of asthma where new therapies are required.

Clearly more clinical and mechanistic data is needed to establish a place for this encouraging new treatment approach in the management of chronic asthma.

\section{References}

1. Bousquet J. Global initiative for asthma (GINA) and its objectives. Clin Exp Allergy 2000; 30: Suppl. 1, 2-5.
2. Boushey HA, Fahy JV. Targeting cytokines in asthma therapy: round one. Lancet 2000; 356: 2114-2116.

3. Rabe KF, Vermeire PA, Soriano JB, Maier WC. Clinical management of asthma in 1999: the Asthma Insights and Reality in Europe (AIRE) study. Eur Respir J 2000; 16: 802-807.

4. Busse WW, Banks-Schlegel S, Wenzel SE. Pathophysiology of severe asthma. J Allergy Clin Immunol 2000; 106: 1033-1042.

5. Solèr M, Matz J, Townley $\mathrm{R}$, et al. The anti-IgE antibody omalizumab reduces exacerbations and steroid requirement in allergic asthmatics. Eur Respir $J$ 2001; 18: 254-261.

6. Milgrom H, Fick RB Jr, Su JQ, et al. Treatment of allergic asthma with monoclonal anti-IgE antibody. rhuMAb-E25 Study Group. N Engl J Med 1999; 341: 1966-1973.

7. Burrows B, Martinez FD, Halonen M, Barbee RA, Cline MG. Association of asthma with serum IgE levels and skin-test reactivity to allergens. $N$ Engl J Med 1989; 320: 271-277.

8. Oettgen HC, Geha RS. IgE regulation and roles in asthma pathogenesis. J Allergy Clin Immunol 2001; 107: 429-440.

9. Coyle AJ, Wagner K, Bertrand C, Tsuyuki S, Bews J, Heusser C. Central role of immunoglobulin (Ig) E in the induction of lung eosinophil infiltration and $\mathrm{T}$ helper 2 cell cytokine production: inhibition by a nonanaphylactogenic anti-IgE antibody. J Exp Med 1996; 183: 1303-1310.

10. Fahy JV, Fleming HE, Wong HH, et al. The effect of an anti-IgE monoclonal antibody on the early- and late-phase responses to allergen inhalation in asthmatic subjects. Am J Respir Crit Care Med 1997; 155: $1828-1834$.

11. Adelroth E, Rak S, Haahtela T, et al. Recombinant humanized $\mathrm{mAb}-\mathrm{E} 25$, an anti-IgE $\mathrm{mAb}$, in birch pollen-induced seasonal allergic rhinitis. $J$ Allergy Clin Immunol 2000; 106: 253-259.

12. Humbert M, Menz G, Ying S, et al. The immunopathology of extrinsic (atopic) and intrinsic (nonatopic) asthma: more similarities than differences. Immunol Today 1999; 20: 528-533. 